\title{
Synemin Redefined: Multiple Binding Partners Results in Multifunctionality
}

\author{
Mary A. Russell* \\ Department of Biological Sciences, Kent State University at Trumbull, Warren, OH, United States
}

Historically synemin has been studied as an intermediate filament protein. However, synemin also binds the type II regulatory $(R)$ subunit $\alpha$ of protein kinase $A(P K A)$ and protein phosphatase type 2A, thus participating in the PKA and phosphoinositide 3kinase (PI3K)-Akt and signaling pathways. In addition, recent studies using transgenic mice indicate that a significant function of synemin is its role in signaling pathways in various tissues, including the heart. Recent clinical reports have shown that synemin mutations led to multiple cases of dilated cardiomyopathy. Additionally, a single case of the rare condition ulnar-mammary-like syndrome with left ventricular tachycardia due to a mutation in the synemin gene (SYNM) has been reported. Therefore, this review uses these recent studies to provide a new framework for detailed discussions on synemin tissue distribution, binding partners and synemin in disease. Differences between $\alpha-$ and $\beta$-synemin are highlighted. The studies presented here indicate that while synemin

OPEN ACCESS

Edited by:

Greg B. Moorhead,

University of Calgary, Canada

Reviewed by:

Onnik Agbulut,

Université Pierre et Marie Curie,

France

Omar Skalli,

University of Memphis, United States

*Correspondence:

Mary A. Russell

mrussel1@kent.edu

Specialty section:

This article was submitted to

Signaling,

a section of the journal

Frontiers in Cell and Developmental

Biology

Received: 20 January 2020

Accepted: 27 February 2020

Published: 17 March 2020

Citation:

Russell MA (2020) Synemin Redefined: Multiple Binding Partners

Results in Multifunctionality.

Front. Cell Dev. Biol. 8:159.

doi: 10.3389/fcell.2020.00159 does function as an intermediate filament protein, it is unique among this large family of proteins as it is also a regulator of signaling pathways and a crosslinker. Also evident is that the dominant function(s) are isoform-, developmental-, and tissue-specific.

Keywords: synemin, AKAP, PKA, intermediate filament, signal transduction

\section{INTRODUCTION}

Synemin is an unusual and exotic intermediate filament (IF) protein that has functions which extend past the normal role of IF proteins. The protein structure of synemin is unusual due to the head domain being shorter and the tail domains (of $\alpha$ and $\beta$ ) being longer than most members of the IF family of proteins (Titeux et al., 2001; Xue et al., 2004). Synemin is considered "exotic" since it is the only cytoplasmic IF representative currently identified that undergoes alternative splicing (Herrmann and Aebi, 2004; Welch et al., 2010). Another unusual characteristic of synemin is its wide tissue distribution. While most IF proteins are used as differentiation markers due to their cell- or tissue-type specific expression, synemin is widely expressed among a variety of tissues. Additionally, IF proteins are found at discrete locations in the plasma membrane such as in costameres or focal adhesions where they serve as a molecular link (Capetanaki et al., 2007; Jones et al., 2017). Again, in atypical fashion for an IF protein, synemin is found in other (non-junctional) membrane locations in astrocytoma cells and cardiac myocytes (Jing et al., 2005; Russell et al., 2006;

\footnotetext{
Abbreviations: aa, amino acid; AKAP, a-kinase anchoring protein; CDK, cyclin-dependent kinase; CDKI, cyclin-dependent kinase inhibitor; CNS, central nervous system; CREB1, cAMP Responsive Element Binding Protein 1; DGC, dystrophinglycoprotein complex; GFAP, glial fibrillary acidic protein; IF, intermediate filament; IFAP, intermediate filament associated protein; mTOR, mechanistic target of rapamycin; PDK1, phosphoinositide-dependent kinase 1; PI3K, phosphoinositide 3kinase; PIP2, phosphatidylinositol 4,5-bisphophate; PIP3, phosphatidylinositol 3,4,5-triphosphate; PKA, protein kinase A; PNS, peripheral nervous system; PP2A, protein phosphatase type 2A; Rb, retinoblastoma; RII $\alpha$, type II regulatory subunit $\alpha$ of PKA; shRNA, short hairpin RNA.
} 
Pan et al., 2008; Lund et al., 2012). These differences between synemin and other IF proteins are suggestive that synemin has additional functions, and, indeed, it has additional binding partners that are not IF proteins. In fact, two binding partners are signaling molecules; thus, suggesting of a role in their associated signaling pathways [i.e., the protein kinase A (PKA) and phosphoinositide 3-kinase (PI3K)-Akt signaling pathways] (Russell et al., 2006; Pitre et al., 2012). In addition, studies using transgenic mice underscore the importance of synemin in multiple signaling pathways, including the PKA and PI3K-Akt pathways, particularly in bone and muscle tissue (Li et al., 2014; Garcia-Pelagio et al., 2015, 2018; Moorer et al., 2016). Further evidence of the functional importance of synemin includes reports of mutations in synemin leading to heart disease and a rare condition that affects multiple tissues including bone and heart (ulnar-mammary-like syndrome) (Zeller et al., 2006; Ware et al., 2016; Zhang et al., 2018; Zlotina et al., 2018). Taken together these findings indicate synemin is an important regulator of multiple signaling pathways and its functions are clinically significant.

This review strives to accomplish 3 tasks: (1) to describe synemin in light of its initial characterization as an IF protein; (2) to provide detailed information on synemin's binding partners; and (3) to offer a fresh outlook on the function of synemin by highlighting new information gleaned from studies using knockout mice and diseases caused by synemin mutations.

\section{IDENTIFICATION OF SYNEMIN AS IN INTERMEDIATE FILAMENT PROTEIN}

Synemin was first identified as an IF-associated protein (IFAP). It was isolated from chicken smooth and skeletal muscle in association with desmin and vimentin at the Z-disks (Granger and Lazarides, 1980). However, cloning of the synemin gene (SYNM) revealed it to be a bona fide IF protein, as it contains the rod domain that allows IF proteins to form coiled-coils dimers which are assembled into $10 \mathrm{~nm}$ filaments (Becker et al., 1995; Bellin et al., 1999; Herrmann and Aebi, 2004). While only one isoform of synemin is expressed in chicken, three isoforms are differentially expressed in mammals; $\alpha$-/high $(\mathrm{H}, 180 \mathrm{kDa}) ; \beta$ /medium (M, $150 \mathrm{kDa}$ ); and, low (L, $41 \mathrm{kDa}$ ) (Titeux et al., 2001; Xue et al., 2004). Even though chicken synemin is most similar to the largest mammalian isoform, it only displays $37 \%$ overall sequence identity. Due to this low sequence homology between orthologs, human synemin was first identified as a novel gene and named desmuslin (Mizuno et al., 2001) which was later found to be $\beta$-synemin (Titeux et al., 2001).

\section{STRUCTURE OF SYNEMIN PROTEIN}

IF proteins have three domains: a head domain, a central rod domain, and a tail domain. The approximately 310 amino acid central rod domain is able to form the alpha-helical coiled-coil used in forming IFs. IF head and tail domains are of varying lengths (Geisler and Weber, 1982; Quax-Jeuken et al., 1983). Both $\alpha$ - and $\beta$-synemin have an unusually short head domain (10 aa) and unusually long C-terminal tails compared to most other IF proteins (Bellin et al., 1999; Titeux et al., 2001). These two differ by the inclusion of one exon in $\alpha$-synemin [4b, as illustrated in Izmiryan et al. (2010)] which encodes a 312 aa insert near the end of the C-terminal tail (Figure 1). A recently identified isoform, $\mathrm{L}$ synemin, shares the head and rod domain of $\alpha$ - and $\beta$-synemin. However, fusion of exon 3 to exon 5 results in the use of a different open reading frame, producing a distinctive, smaller, C-terminal tail (Xue et al., 2004). Most research, including ours, is carried out on $\alpha$-and/or $\beta$-synemin, thus, these isoforms will be the primary focus of the rest of this review.

\section{SYNEMIN AS AN IF PROTEIN}

IF networks are one of three structural components of the cytoskeleton along with microtubules and actin microfilaments. The IF super family is expressed in all metazoan cells in a celland tissue-specific dependent manner. The function of IFs varies with cell type and ranges from cell motility to signal transduction (Fuchs and Weber, 1994; Coulombe and Wong, 2004; Herrmann and Aebi, 2004; Eriksson et al., 2009; Lowery et al., 2015). IF proteins are grouped into six types (I-VI) based on sequence homology, gene structure and tissue distribution (Herrmann and Aebi, 2000, 2016; Sanghvi-Shah and Weber, 2017). In the past, synemin, together with nestin, tanabin, and transitin have been classified as type VI IFs due to sequence similarity and genomic organization (Steinert et al., 1999; Titeux et al., 2001; Guerette et al., 2007), but more recently this group has been folded into the type IV neurofilament IFs due to being similar in gene structure and also to only being found in vertebrates (Herrmann and Aebi, 2000; Peter and Stick, 2015).

Synemin is not able to form homopolymeric IFs due to deficiencies in the head and rod domain (Khanamiryan et al., 2008), instead it forms heteropolymers usually with type III IF proteins in a tissue-dependent manner. Synemin's IF binding partners (and non-IF binding partners) are discussed in detail below.

\section{SYNEMIN BINDING PARTNERS}

The diversity among C-terminal tails of is thought to provide functional differences among the IF proteins (Guerette et al., 2007; Herrmann and Aebi, 2016). That coupled with the fact that the two large synemin isoforms differ only in the C-terminal tail argues that the functional differences are due to this structural difference. This difference appears to lead to differences in subcellular distribution and/or binding partners.

In support of differential subcellular distribution, $\alpha$-synemin was found primarily at the sarcolemma and intercalated discs (i.e., sites of cell-cell contact) while $\beta$-synemin localized primarily at the Z-disks in neonatal cardiac myocytes (Lund et al., 2012). Synemin's multiple binding partners within costameres (discussed in the section Binding Partners at Costameres/Focal Adhesions) are likely responsible for localization of synemin 


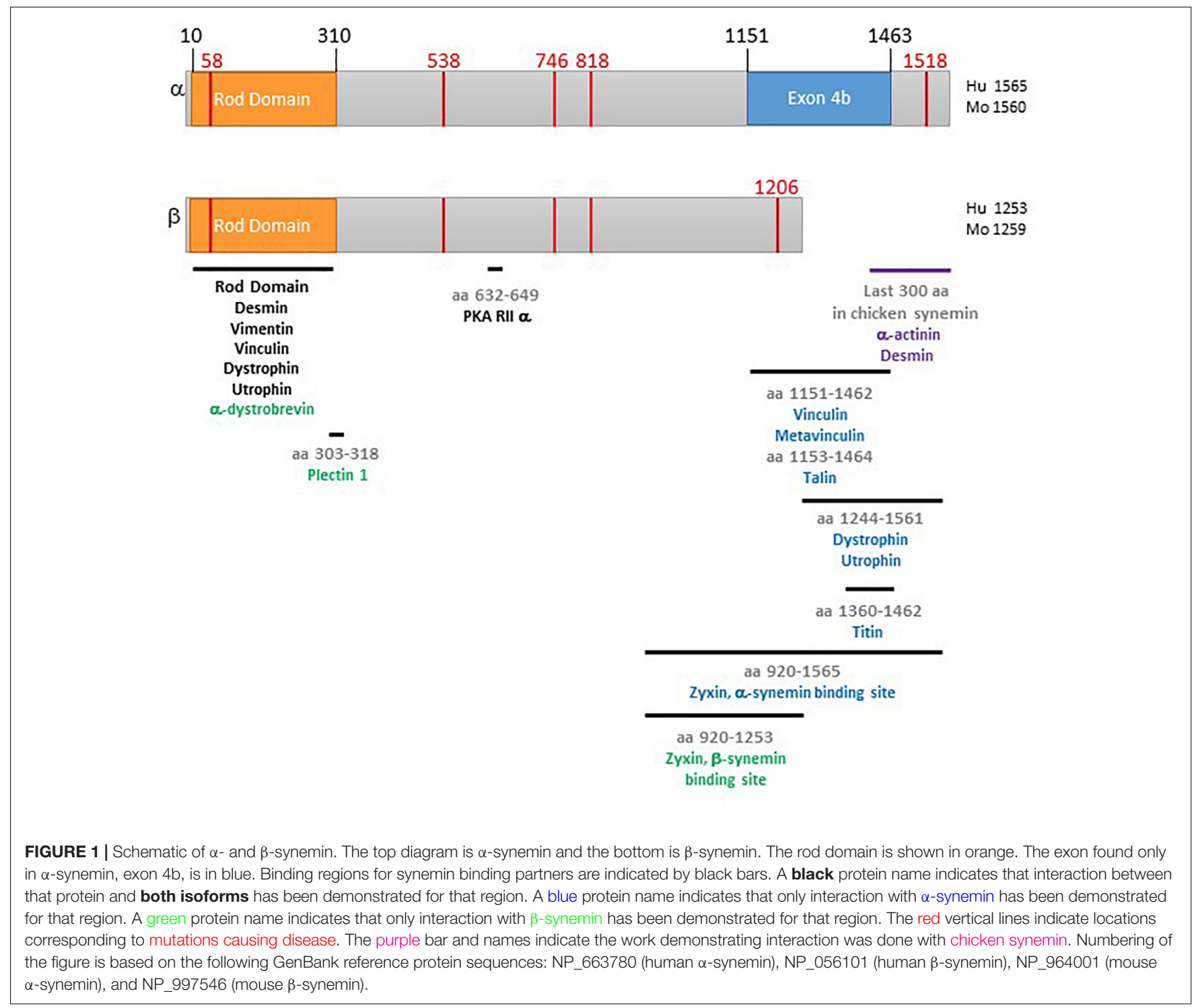

to these junctional membrane locations. Synemin localized in non-junctional membrane was shown to co-localize with desmin and $\alpha$-actinin in neonatal cardiac myocytes and U-373 MG cells (human glioblastoma cells), respectively (Jing et al., 2005; Pan et al., 2008; Lund et al., 2012).

Many studies have focused on investigating synemin binding partners and some have identified isoform specific binding. Below, the plethora of $\alpha$ - and $\beta$-synemin binding partners and the subcellular locations of each isoform is discussed. Figure 1, a schematic of $\alpha$ - and $\beta$-synemin, illustrates the current state of knowledge as to the region(s) of interaction on each synemin isoform for their binding partners.

\section{IF Network Binding Partners}

IF networks in striated muscle localize to Z-disks maintaining lateral alignment of myofibrils (Paulin et al., 2004; Capetanaki et al., 2007). As previously mentioned, synemin forms obligate heteropolymeric IFs, usually with a type III IF protein. For example, its copolymerizing partner in developing and mature muscle is vimentin and desmin, respectively (Granger and Lazarides, 1980; Bilak et al., 1998; Bellin et al., 1999; Mizuno et al., 2001). In desmin knock-out mice, synemin is no longer found at the Z-disks in skeletal muscle (Carlsson et al., 2000). Synemin binds desmin and vimentin via the rod domain (Bellin et al., 2001; Mizuno et al., 2001; Figure 1). Both synemin isoforms have the ability to interact with desmin and vimentin as demonstrated with transfection studies and co-immunoprecipitation analysis (Mizuno et al., 2001; Titeux et al., 2001; Jing et al., 2007; Hijikata et al., 2008).

Synemin was shown to co-localize with glial fibrillary acidic protein (GFAP), another type III IF protein, in astrocyte progenitor cells and astrocytoma cells, hepatic stellate cells, and non-myelin-forming Schwann cells (Hirako et al., 2003; Jing et al., 2005; Uyama et al., 2006). In vitro blot overlay and co-immunoprecipitaion studies further suggested IF network formation between GFAP and synemin (Hirako et al., 2003; 
Uyama et al., 2006). However, research with GFAP null mice suggests that synemin does not form IFs with GFAP in astrocytes, instead using vimentin as its polymerizing partner in these cells. Rather, it interacts with GFAP as an IFAP (Jing et al., 2007).

One study has shown that in myoepithelial cells synemin may form heteropolymers with type II IF proteins, the basic cytokeratins. Immunofluorescence microscopy showed that synemin co-localizes to the keratin cytoskeleton; additionally, anti-synemin antibody co-immunoprecipitated both cytokeratin 5 and 6 but not acidic cytokeratin 14 (IF type I) (Hirako et al., 2003).

\section{Role of Synemin as an IF Protein}

The functional role of synemin as an IF protein has recently been addressed via transgenic animal studies. Because synemin is a minor component of IF filaments (i.e., in a ratio of $\sim 50: 1$ with vimentin and $\sim 25: 1$ with desmin) (Granger and Lazarides, 1982; Hirako et al., 2003) it is not surprising that synemin null mice displayed minor skeletal and cardiac phenotypes related to IF networks. For example, desmin localized correctly in mature striated muscle (Li et al., 2014; Garcia-Pelagio et al., 2015, 2018). One study did find minor sarcomere abnormalities in soleus muscle in old mice which might be attributed to the loss of synemin from the IF network ( $\mathrm{Li}$ et al., 2014). However, a different study detected no sarcomere changes in tibialis anterior muscle (Garcia-Pelagio et al., 2015). These differences could be due to the methods used to disrupt the synemin gene, different types of skeletal muscle studied [soleus (slow) vs. tibialis anterior (fast)] or the specific length of fibers chosen to study, each group focused on fibers with different average sarcomere length.

Synemin is not restricted to IF networks, it is found in multiple other locations in various cell types. It has been most extensively studied in muscle, but studies in various cells of the nervous system, in particular astrocytes, and other cell types have also been described. At these other locations synemin is found in association with non-IF binding partners.

\section{Signaling Molecules as Binding Partners}

IF proteins have recently been recognized as multivalent scaffolding proteins. This is exciting because it potentially allows synemin and other IF proteins to act upon various cellular activities including signal transduction (Coulombe and Wong, 2004; Eriksson et al., 2009). Accordingly, it has been shown that synemin regulates two signaling pathways: the PKA and the PI3K-AKT pathways (Russell et al., 2006; Pitre et al., 2012).

\section{The PKA Pathway (Synemin Is an AKAP)}

A region in the $\mathrm{C}$-terminal tail common to $\alpha$ - and $\beta$-synemin is able to bind the regulatory (R) subunit of PKA type II $\alpha$ (aa 632-649, Figure 1; Russell et al., 2006), this classifies synemin as an AKAP. AKAPs are a large structurally diverse family which share a small motif that allows them to bind to the regulatory subunit of PKA. Upon activation of PKA by binding of cAMP to the $\mathrm{R}$ subunits, the $\mathrm{C}$ subunits then dissociate and phosphorylate nearby substrates (Scott, 1991). PKA has broad substrate specificity yet is highly selective in a physiological setting. Anchoring of PKA near its substrates via AKAPs is one mechanism used to enhance specificity of the pathway. The ability of AKAPs to tether PKA to specific subcellular locations near physiological substrates is thought to confer specificity on multiple PKA signaling pathways operating in the same cell; in this way different PKA pathways are initiated via a different receptors and end in different physiological outcomes in the same cell (Lester and Scott, 1997; Carnegie et al., 2009). Additionally, many AKAPs are multivalent scaffolds, binding other proteins such as upstream activators like adenylyl cyclase, downstream repressors like phosphatases and phosphodiesterases, and members of other signaling pathways like PKC (Welch et al., 2010; Calejo and Tasken, 2015; TorresQuesada et al., 2017). This co-localization of multiple signaling pathway participants is thought to allow AKAPs to not only enhance specificity, but to also amplify and accelerate signaling, and to reduce basal activity of PKA (Feliciello et al., 2001; Greenwald and Saucerman, 2011).

In the heart, AKAP-mediated anchoring of PKA regulates contractility (Fink et al., 2001). To date, at least 17 AKAPs and their associated splice variants have been identified in cardiac myocytes (Kritzer et al., 2011). Stimulation of the $\beta$-adrenergic pathway in cardiac myocytes results primarily in activation of PKA, including the AKAP-anchored pools distributed to discrete locations throughout the cardiac myocyte near PKA substrates. This allows for the catalytic subunit to phosphorylate various targets including the L-type $\mathrm{Ca}^{+}$channel, ryanodine receptor, phospholamban, troponin $\mathrm{I}$, and myosin binding protein $\mathrm{C}$ (Brum et al., 1984; Yoshida et al., 1992; Zhang et al., 1995; Weisberg and Winegrad, 1996; Karczewski et al., 1997). These PKA substrates work in concert upon activation to increase the force of contraction and rate of relaxation. To date, the specific role of synemin-anchored PKA is not known.

\section{The PI3K-AKT Pathway}

Synemin is expressed in astrocyte progenitor cells but not mature astrocytes (Sultana et al., 2000). It is re-expressed in these cells, however, under pathophysiological conditions, in reactive astrocytes and glioblastoma tumors as discussed in the section Changes in Synemin Expression: Astrocytes (Jing et al., 2005; Pan et al., 2008). RNAi experiments in multiple human glioblastoma cell lines revealed synemin enhances the migratory properties of astrocytoma cells and plays a role in enhancing glioblastoma cell proliferation through its effects on the PI3K-Akt signaling pathway (Pan et al., 2008; Pitre et al., 2012). This pathway is critical for controlling the G1/S transition and thus proliferation (Liang and Slingerland, 2003).

Under normal conditions PI3K can be stimulated by various extracellular signals such as growth factors and hormones (Shi et al., 2019). Upon stimulation, PI3K converts phosphatidylinositol 4,5-bisphophate (PIP2) into phosphatidylinositol 3,4,5-triphosphate (PIP3) (Rubashkin et al., 2014). This results in recruitment of Akt (also called protein kinase B) and phosphoinositide-dependent kinase 1 (PDK1) to the membrane. PKD1 phosphorylation of Akt leads to partial activation. Complete activation is accomplished by phosphorylation at a second site by mTOR complex 2 (Sarbassov et al., 2005; Yu and Cui, 2016). Active Akt prevents 
accumulation of two cyclin-dependent kinase inhibitors (CDKIs), p21 ${ }^{\mathrm{Cip} 1}$ and $27^{\mathrm{Kip} 1}$ (Li et al., 2002; Vervoorts and Luscher, 2008; Lee and Kim, 2009). In the absence of CDKIs, the cell cycle is able to progress from $\mathrm{G} 1$ to $\mathrm{S}$ due to cyclins binding to and activating cyclin-dependent kinases (CDKs) which phosphorylate retinoblastoma (Rb), a tumor suppressor protein. Once phosphorylated, $\mathrm{Rb}$ is no longer able to inhibit transcription of several genes needed to enter $S$ phase (Knudsen and Knudsen, 2008).

Reducing synemin in glioblastoma cell lines led to decreased phosphorylation of Akt and $\mathrm{Rb}$ and an increase in protein levels of $\mathrm{p} 21^{\mathrm{Cip} 1}$ and $\mathrm{p} 27^{\mathrm{Kip} 1}$. This was accompanied by a reduction of cell proliferation due to a decrease in cells moving past the G1/S transition. These results led Pitre et al. (2012) to investigate the PI3K-Akt pathway. They found $\alpha$ and $\beta$-synemin bind to protein phosphatase type 2A (PP2A), the phosphatase primarily responsible for dephosphorylation of the Akt residues hypophosphorylated in these studies (Ruvolo, 2016). They proposed the role of synemin in these cells is to bind PP2A and sequester it away from Akt. Thus, a loss of synemin led to dephosphorylation and inactivation of Akt which allowed accumulation of the CDKIs p21 Cip1 and $\mathrm{p} 27^{\mathrm{Kip} 1}$ leading to inhibition of $\mathrm{CDKs}$ and reduction of $\mathrm{Rb}$ phosphorylation and loss of progression through the cell cycle. The PP2A binding site on synemin has not been determined.

\section{Role of Synemin in Signaling Pathways}

Transgenic animal studies emphasize the importance of synemin in signaling pathways. In skeletal muscle, knockout mice displayed increased hypertrophy in response to overload and a decreased rate of fatigue compared to controls ( $\mathrm{Li}$ et al., 2014; Garcia-Pelagio et al., 2015). The changes in synemin null mice were ascribed to a host of changes in gene expression and post-translational modification. Specifically, analysis of gene expression by PCR revealed decreased expression of two negative regulators of muscle mass (atrogin and myostatin) and increased expression of two positive regulators of muscle mass (follistatin and muscle-specific IGF1) (Li et al., 2014). These were accompanied by an increase in total protein as well as phosphorylated forms of several proteins that play a role in muscle hypertrophy (PKA RII $\alpha$, Akt, CREB1, and ribosomal protein S6). The reduced tibialis anterior and quadriceps muscle fiber size seen in mice lacking synemin was also attributed to these changes in signaling proteins (Garcia-Pelagio et al., 2015).

The role of synemin as an AKAP is highlighted by the fact that PKA activity was increased in mice lacking synemin ( $\mathrm{Li}$ et al., 2014). The authors suggest that the role of synemin may be to hold PKA inactive in skeletal muscle. This role for synemin as an AKAP would explain why a loss of synemin in null mice resulted in increased PKA activity which then resulted in an increase in phosphorylation of PKA substrates (RII $\alpha$, CREB1, and ribosomal protein S6). The increase in Akt phosphorylation in skeletal muscle in synemin null mice is in contrast to the reduction seen in glioblastoma cell lines treated with synemin shRNA. The difference might be due to tissue-type specificity of synemin and/or PP2A functions
(Ruvolo, 2016) or different experimental models (cell lines vs. transgenic mice).

One study has focused exclusively on the role of synemin in the heart using synemin null mice (Garcia-Pelagio et al., 2018). The resulting phenotype in old mice, a mixture of changes associated with both hypertrophic and dilated cardiomyopathy, illustrates the important yet complex role of synemin in the heart. For example, an increase in the size of cardiac myocytes, in the diastolic pressure, and in left ventricular mass indicated hypertrophic cardiomyopathy. However, a decrease in left ventricular ejection fraction and fractional shortening indicated dilated cardiomyopathy. Therefore, a loss of synemin resulted in heart disease in old mice, even young mice displayed reduced left ventricular contractility. The physiological results of impaired ejection and contractility correlate with cellular results in synemin null mice; a decrease in magnitude of sarcomere shortening and a decrease in $\mathrm{Ca}^{+}$transient amplitude. The authors speculate that the most likely cause of the mixed phenotype is due to changes in either PKA or extracellular signalregulated kinase $1 / 2$. Western blot analysis indicated a decrease in the phosphorylation level of both proteins in synemin null mice, and each play a role in cardiac contractility and hypertrophy (Dhalla and Müller, 2010; Rose et al., 2010; Mutlak and Kehat, 2015; Callaghan, 2016).

In light of the fact that increased phosphorylation of RII enhances affinity of the PKA holoenzyme for its AKAP (Zakhary et al., 2000), it is interesting that, in mice lacking synemin, there was a differential response with respect to the phosphorylation of RII. Specifically, there was an increase in the phosphoprotein in skeletal muscle and a decrease in cardiac muscle (Li et al., 2014; Garcia-Pelagio et al., 2018). These differences could be tissue-specific or due to differences in methods used to interrupt the synemin gene. The increase in RII phosphorylation in skeletal muscle was probably due to the increase in PKA activity in synemin null mice ( $\mathrm{Li}$ et al., 2014). (PKA activity was not assayed in cardiac myocytes). In each case, changes in RII phosphorylation may lead to changes in interaction between PKA and the other AKAPs. For example, since synemin is only one of approximately 17 AKAPs in cardiac myocytes (Kritzer et al., 2011), a decrease in RII $\alpha$ phosphorylation could result in reduced AKAP/PKA interaction and could be the cause of the reduction of PKA substrate phosphorylation. Furthermore, it is of particular note that AKAP-PKA interactions are altered in failing human hearts (Aye et al., 2012).

Researchers found that that synemin null mice had pronounced bone loss (Moorer et al., 2016). This was due to a reduction of osteoblasts leading to reduced bone formation. At a molecular level, synemin null mice exhibited a reduction of cyclin D1 mRNA expression in primary osteoblasts which coincided with enhanced osteogenic capacity. Interestingly, in primary osteoblasts from control mice, synemin was not in the IF network, instead it displayed punctate cytoplasmic staining. The authors speculated that the AKAP functionality of synemin might be responsible for the osteopenia because PKA plays a role in bone formation and osteoblast and osteoclast differentiation. However, it should be mentioned 
that the PI3K-Akt is also important in bone formation (Kawamura et al., 2007; Mukherjee and Rotwein, 2009; McGonnell et al., 2012).

It is important to note that a study assessing the role of synemin and vimentin in endothelial cells and vascular smooth muscle cells generated synemin null, vimentin null, and double knock-out mice (Langlois et al., 2017). The results indicate that the role of synemin in the parameters under study were practically all related to the functions of vimentin. Synemin null mice were not different from control animals. These findings strengthen the idea that the functions of synemin are tissue-specific.

\section{Binding Partners at the Sarcomere}

In muscle cells, in addition to forming IF networks which are around the $Z$-disks, synemin binds to $\alpha$-actinin, an integral component of the Z-disks. In these cells, $\alpha$-actinin participates in cross-linking sarcomeric actin and linking the actin filaments to the costameres through its various other protein interactions (Capetanaki et al., 2007; Sjoblom et al., 2008; Henderson et al., 2017). Several studies have demonstrated that synemin binds $\alpha$-actinin. Blot overlay and yeast two-hybrid studies showed that the binding site on chicken synemin is in the final 300 amino acids (aa 1292-1604) (Bellin et al., $1999,2001)$. In neonatal cardiac myocytes, $\beta$-synemin coimmunoprecipitated with $\alpha$-actinin and localized to Z-disks (Lund et al., 2012).

In human glioblastoma cell lines synemin co-localized with $\alpha$-actinin at ruffled membranes, which are cellular domains active in cell motility. Interaction of the two proteins was further demonstrated by co-immunoprecipitation (Jing et al., 2005; Pan et al., 2008).

It should be noted that two studies probed for interaction between synemin and $\alpha$-actinin via co-immunoprecipitation but were unable to identify any interaction (Uyama et al., 2006; Hijikata et al., 2008). The discrepancies in these findings with those described above could be due to differences in cell type and/or antibodies used.

Synemin has a second binding partner within the sarcomere. Specifically, $\alpha$-synemin binds to the final domain of titin (the M10 region) positioning this isoform at the M-band of the sarcomere in cardiac muscle cells. The titin binding region of $\alpha$-synemin is the final 102 amino acids of 312 amino acid insert that differentiates $\alpha$ - and $\beta$-synemin (Prudner et al., 2014). Titin, the largest protein in mammals, is a component of striated muscle, and spans half a sarcomere. Its $\mathrm{N}$-terminal end is at the Z-disk and its C-terminal end is at the M-band. Functionally, it plays a role in the passive stiffness of cardiac myocytes (Hidalgo and Granzier, 2013). The role of $\alpha$-synemin at the M-band is not known, but it is not likely to be related to a structural function based on the observation that down regulation of synemin did not result in disruption of $\mathrm{M}$-band organization in neonatal cardiac myocytes (Lund et al., 2012). Additionally, in synemin null mice, the M-band in skeletal and cardiac myocytes developed normally (Li et al., 2014; Garcia-Pelagio et al., 2018). Even though titin itself is a PKA substrate, the phosphorylation sites are near the Z-disk end of the molecule, thus not likely to be substrates of $\alpha$-synemin anchored PKA at the M-band.

\section{Binding Partners at Costameres/Focal Adhesions}

Costameres (found in muscle cells) are akin to focal adhesion complexes in non-muscle cells. Costameres are located just below the sarcolemma in register with the Z-disk and, possibly, the M-band. IFs extend from the sarcomere to the costameres, linking the Z-disk to the sarcolemma. Within costameres are two protein complexes, the vinculin-talin-integrin system and the dystrophin-glycoprotein complex (DGC). Each provides a link from the interior of the cell to the extracellular matrix allowing for both "in-side out" and "out-side in" transfer of information (Ervasti, 2003; Peter et al., 2011; Cutroneo et al., 2012; Henderson et al., 2017). Interestingly, synemin is capable of binding proteins in each complex: vinculin and talin in the vinculin-talin-integrin complex (Bellin et al., 2001; Uyama et al., 2006; Sun et al., 2008b); and, $\alpha$-dystrophin and $\alpha$-dystrobrevin in the DGC (Mizuno et al., 2001; Bhosle et al., 2006).

Vinculin is expressed in all cells where it localizes to focal adhesions. Therefore, in muscle cells it is found at the costamere, specifically in the vinculin-talin-integrin complex. It links actin filaments to the sarcolemma. The vinculin binding site on synemin was localized to amino acids 1292-1604 in chicken synemin (Bellin et al., 2001). There are conflicting studies on the interaction between vinculin and mammalian synemin isoforms. In one study, human $\alpha$-synemin was shown to interact with vinculin via blot overlays while $\beta$-synemin did not. In this study, the only region of interaction was mapped to a region found only in $\alpha$-synemin, amino acids 1151-1462 (Figure 1). They also revealed interaction between $\alpha$-synemin and metavinculin (a splice variant of vinculin) albeit, at a lower affinity than that for vinculin (Sun et al., 2008a). Immunostaining and co-immunoprecipitation in hepatic stellate cells also indicated interaction and co-localization of synemin and vinculin, the specific isoform of synemin was not confirmed in these studies (Uyama et al., 2006). However, in contrast to the first mammalian study described, $\beta$-synemin and vinculin were co-immunoprecipitated in two studies; specifically from rat skeletal muscle and rat neonatal cardiac myocytes (Hijikata et al., 2008; Lund et al., 2012). Additionally, Lund et al. (2012) did not detect interaction between synemin and metavinculin. These discrepancies could be due differences in methodologies, cell types, and/or cell development.

Talin mediates interaction between the extracellular matrix and the vinculin-talin-integrin complex. More specifically, it binds integrins and vinculin and thus links integrins to the sarcomere (Henderson et al., 2017; Klapholz and Brown, 2017). Studies in skeletal muscle and hepatic stellate cells showed synemin co-immunoprecipitated and co-localized with talin at costameres/focal adhesion complexes (Uyama et al., 2006; Sun et al., 2008b). The synemin binding site was localized to the $\alpha$-synemin specific region, amino acids 1153-1464 (Figure 1; Sun et al., 2008b). Since this binding region had already been shown to be a binding site for vinculin, binding assays were 
carried out and it was determined that interaction within this region of synemin with vinculin and talin are mutually exclusive (Sun et al., 2008a,b).

Dystrophin is a large protein found in the DGC. Through its interaction with $\beta$-dystroglycan at the sarcolemma and actin filaments, dystrophin links the DGC to the cytoskeleton (Gao and McNally, 2015). Utrophin is a homolog of dystrophin found mostly in the DGC in neuromuscular junctions and myotendinous junctions in adult muscle (Perkins and Davies, 2002). The rod domain common to both synemin isoforms bound both utrophin and dystrophin in blot overlay and pulldown assays. Additionally, both utrophin and dystrophin bound to an $\alpha$-synemin fragment containing the final 391 amino acids of C-terminal tail (Figure 1). Synemin and dystrophin co-localized in a rat smooth muscle cell line (Bhosle et al., 2006). The antibody used to detect synemin recognizes both isoforms. Thus, in vivo, it is unclear if dystrophin binds to both isoforms via the rod domain or just $\alpha$-synemin through two interaction sites. It is tempting to speculate, based on the differential distribution seen in neonatal cardiac myocytes, in which $\alpha$-synemin (but not $\beta$-synemin) was found at the sarcolemma and sites of cell-cell contact (Lund et al., 2012), that $\alpha$-synemin is more likely to be found at the costameres due to multiple interaction sites.

In muscle cells, $\alpha$-dystrobrevin is found in the DGC. It is part of a series of protein interactions that helps to hold the DGC together, the sarcoglycan-dystrobrevin-dystrophin complex (Gao and McNally, 2015). Yeast two-hybrid analysis revealed that $\beta$-synemin is able to bind $\alpha$-dystrobrevin. Further analysis localized the synemin binding region to the rod domain (Mizuno et al., 2001). The two proteins co-localize in rat skeletal muscle (Hijikata et al., 2008). The ability of $\alpha$-synemin to bind to $\alpha$-dystrobrevin has not been tested, but, since the rod domain is identical in these two isoforms, it would be possible. Additionally, as previously mentioned, $\alpha$-synemin has been shown to be the predominant isoform at the sarcolemma (Lund et al., 2012).

Zyxin is an LIM domain protein that shuttles from focal adhesions to the Z-disk and the nucleus. One of the many proteins it binds is $\alpha$-actinin and its nuclear export signal facilitates its movements into and out of the nucleus. It is thought that zyxin responds to mechanical stress and then moves into the nucleus to activate gene expression related to cell survival (Brancaccio et al., 2006; Henderson et al., 2017). $\alpha$ - and $\beta$-synemin bind to the LIM domain repeats of zyxin. The binding region on synemin was mapped to the final ends of the C-terminal tails ( $\alpha$-synemin aa $920-1565, \beta$-synemin aa 920-1253; Figure 1). Overexpression of the $\beta$-synemin binding region in three different cell types (HeLa, A-10, NIH 3T3) led to loss of zyxin at focal adhesions. When tested in HeLa cells, overexpression of a synemin peptide encompassing the zyxin binding region resulted in decreased adhesion and increased migration. While reduction of synemin via siRNA did not result in changes in zyxin localization, these cells did display significantly compromised adherence and migration. Therefore, it appears synemin does promotes adhesion and migration in HeLa cells; but, the role, if any, of zyxin in this function is still not clear (Sun et al., 2010).

\section{Other Binding Partners}

Plectin 1 is an IF associated protein that, in general, connects all non-muscle cytoskeletal networks. In muscle cells it is found at various membrane locations such as desmosomes, intercalated discs, costameres and Z-disks. It works to anchor and organize IFs and interact with microtubules and actin microfilaments and also scaffold signaling proteins (Capetanaki et al., 2007; Wiche et al., 2015). Blot overlay assays probing for plectin 1 binding proteins detected $\beta$-synemin. The plectin binding site on $\beta$-synemin was localized to the region around the boundary of the rod and tail domain (Figure 1). $\alpha$-synemin was not tested, but, as seen in Figure 1, the binding site is common to both isoforms so it is possible both can bind to plectin. Pull down assays and colocalization studies confirm interaction between $\beta$-synemin and plectin 1 in muscle cells. Immune complexes containing plectin, $\beta$-synemin, and components of the DGC and cytoskeleton (dystrophin, vinculin/metavinculin, $\alpha$-dystrobrevin, desmin, and actin) were isolated from skeletal muscle (Hijikata et al., 2008).

Due to the unique web of interactions described above, synemin is well poised to crosslink the IF networks to the costameres, i.e., sites that are important for force transmission across the membrane, maintaining mechanical integrity of the membrane, and mechanotransduction (Sanghvi-Shah and Weber, 2017). Synemin is also well positioned to act as a crosslinker of IF networks and the sarcomeres via interaction with $\alpha$-actinin (at the Z-disk) and titin (at the M-band) (Bellin et al., 2001).

\section{Role of Synemin as a Crosslinker}

The role of synemin as a crosslinker was investigated in skeletal muscle using transgenic mice. The loss of interaction between synemin and its binding partners at the sarcolemma were thought to be the cause of membrane "wrinkles" observed in soleus muscle fibers (Li et al., 2014). Similarly, this loss of interaction is thought to be the cause of weaker costameres and a less stable sarcolemma in tibialis anterior muscle fibers (Garcia-Pelagio et al., 2015). In tibialis anterior muscles, these changes led to an increase in susceptibility of skeletal muscle to injury and, following injury, enhanced necrosis compared to controls. At the molecular level, the cause of the phenotype was proposed to be due to the loss of synemin binding to dystrophin and/or $\alpha$-dystrobrevin; these proteins are found in the DGC and loss of DGC proteins leads to a similar outcome (Peter et al., 2011; Garcia-Pelagio et al., 2015).

\section{SYNEMIN TISSUE DISTRIBUTION: NORMAL TISSUE}

Compared to other IF proteins, synemin has an unusually wide expression pattern. As most research is carried out in muscle and astrocytes, this section will discuss these tissues in depth and the others will be briefly mentioned.

\section{Muscle}

Synemin was first identified in chicken smooth and skeletal muscle (Granger and Lazarides, 1980). It has since been found in 
all three muscle cell types in a variety of species (Bilak et al., 1998; Mizuno et al., 2001; Titeux et al., 2001; Hirako et al., 2003; Xue et al., 2004). Additionally, synemin is also found in myoepithelial tissue, a type of contractile muscle tissue which expresses cytokeratins rather than desmin, where it co-localizes with cytokeratin 5 and 6 as described above (Hirako et al., 2003; Noetzel et al., 2010).

With respect to isoform distribution, as expected, only one synemin isoform is expressed in chicken muscle. However, in mammalian muscle, isoform expression is tissue-specific. In adult tissue, Northern and Western analysis shows $\beta$-synemin is the predominant isoform in cardiac and skeletal muscle (Titeux et al., 2001; Hirako et al., 2003; Xue et al., 2004). Isoform expression in smooth muscle is more complex and varies with the type of smooth muscle. For instance, $\alpha$-synemin was detected only in bladder while $\beta$-synemin was detected in bladder, blood vessels, and stomach (Xue et al., 2004). It is unclear which isoform(s) are expressed in myoepithelial tissue because synemin was detected via immunofluorescence using an antibody that recognizes both isoforms.

Interestingly, the SYNM gene is regulated by myocardinrelated transcription factors in a serum response factorindependent manner (Sward et al., 2019). While this study focused on the role of myocardin-related transcription factors and synemin (among other proteins) in smooth muscle, it is worth mentioning that myocardin-related transcription factors also regulate skeletal and cardiac muscle development (Wang et al., 2001; Parmacek, 2007; Cenik et al., 2016). Whether or not these transcription factors regulate SYNM in striated tissue is currently unknown.

\section{Astrocytes}

In addition to striated muscle, synemin has been extensively studied in astrocytes. Its expression is tissue and/or species specific as it is expressed only in astrocyte progenitor cells under normal conditions in rat and human brain (Sultana et al., 2000; Izmiryan et al., 2010). But it is expressed in mature astrocytes of the optic nerves in adult bovine and rabbit (Hirako et al., 2003). This difference may be species specific and/or attributed to the fact that the astrocytes in the optic nerve expresses vimentin in addition to GFAP. Synemin has been shown to have a preference for forming IFs with vimentin rather than GFAP in astrocytes as detailed above (Jing et al., 2007). Under normal conditions, synemin is not expressed in adult astrocytes, however, it is reexpressed in mature astrocytes in the human brain due to trauma or cancer (Jing et al., 2005). This is discussed in detail below in the section Changes in Synemin Expression: Astrocytes.

It is highly likely that $\alpha$-synemin is the isoform expressed in astrocyte progenitor cells based on the molecular weight of the single band detected in those cells and the fact that the larger isoform is more abundant than the smaller one under pathophysiological conditions (Sultana et al., 2000; Jing et al., 2005).

\section{Other Tissues}

Early research detected synemin in chicken erythrocytes and lens cells (Granger and Lazarides, 1980; Granger et al., 1982). In mammals, synemin has been discovered in lens cells, the retina, the CNS and PNS, hepatic stellate cells of the liver, pancreatic stellate cells (this was species specific, detected in rat and mice but not guinea pig), kidney mesangial cells, and peribronchiolar stellate-shapedfibroblasts (Hirako et al., 2003; Tawk et al., 2003; Jing et al., 2005; Izmiryan et al., 2006, 2009, 2010; Schmitt-Graeff et al., 2006; Uyama et al., 2006; Mizuno et al., 2007, 2009; Luna et al., 2010). Synemin is also expressed in embryonic stem cells and adult muscle stem cells, i.e., satellite cells (de Souza Martins et al., 2011; Li et al., 2014; Mukund and Subramaniam, 2020).

\section{SYNEMIN IN DISEASE}

Synemin expression is altered is several pathologies. The most extensive research in this field has been carried out with astrocytes. Recently, synemin mutations have been found in association with disease, in particular, heart disease.

\section{Changes in Synemin Expression: Astrocytes}

Astrocytes exposed to trauma or disease become reactive astrocytes. This term encompasses a suite of changes including changes in gene expression and morphology (Hol and Pekny, 2015). The upregulation of the IF protein GFAP is the commonly used marker for reactive astrocytes, and now it is known that synemin is also upregulated in these cells (Jing et al., 2005). $\alpha$-Synemin was upregulated and $\beta$-synemin, not seen in astrocyte progenitor cells, was also expressed in reactive astrocytes and astrocytoma cells (Jing et al., 2005; Luna et al., 2010). As discussed above, synemin was shown to have a role in glioblastoma cell proliferation due to its ability to bind $\mathrm{PP} 2 \mathrm{~A}$ and sequester it away from Akt (Pitre et al., 2012) and may have a similar role in these pathologies.

Alexander disease is a neurodegenerative disorder caused by mutations in GFAP that cause Rosenthal fibers to form in astrocytes. Synemin has been found in the Rosenthal fibers and in surrounding reactive astrocytes (Pekny et al., 2014). It is currently unknown if the protein aggregates formed by GFAP and synemin contribute to the pathology of the disease.

\section{Changes in Synemin Expression: Other Tissues}

As mentioned earlier, synemin is found in hepatic stellate cells in the liver. Under pathological conditions it is upregulated in hepatic stellate cells and expression becomes more widespread in other cell types of the liver (Schmitt-Graeff et al., 2006). For example, during disease progression periportal fibroblasts become more synemin positive in more advanced fibrosis or cirrhosis. Synemin was also expressed in proliferating biliary epithelial cells and intrahepatic cholangiocarcinoma cells. This is unusual because synemin is not normally expressed in epithelial cells other than the contractile myoepithelial cells. The authors suggested that during liver disease these cells become more contractile-like.

The synemin gene was found to be one of the most frequently down-regulated genes in breast carcinoma tissue (Noetzel et al., 2010). Synemin is expressed in multiple locations 
including the myoepithelial cells of breast lobules and ducts in normal tissue. Very little or no synemin staining was detected via immunostaining in cancerous tissues. Methylation of the promoter was found to be the cause of synemin down-regulation. Loss of synemin correlated with unfavorable recurrence-free survival and positively with lymph node metastases and advanced tumor grade. Thus, it was proposed that loss of synemin production via methylation may be used as a predictive marker for risk of disease relapse.

A genome-wide expression profiling study using samples from patients with bladder exstrophy-epispadias complex identified 162 genes that were differentially expressed. Synemin was one of the two most significantly down-regulated genes (along with desmin) (Qi et al., 2011). Bladder exstrophy-epispadias complex is a spectrum of abnormalities where the distal urinary tract does not close during development. A significant portion of the dysregulated genes were associated with the cytoskeleton and desmosome leading the authors to suggest that the inability of IFs to anchor to the desmosome or abnormal desmosome formation may contribute to the disease.

\section{Synemin Mutations in Disease}

To date, four mutations in the synemin gene (SYNM, GenBank reference sequences NM_145728 and NM_015286) have been linked to dilated cardiomyopathy (Zeller et al., 2006; Ware et al., 2016; Zhang et al., 2018). As shown in Figure 1, each of these mutations are located in the C-terminal tail of synemin. Specifically, two point mutations were found (c.1612T $>\mathrm{C}$ and c.2356G > A) which resulted in the missense mutations W538R and V746M (Zeller et al., 2006; Zhang et al., 2018). A deletion mutation (c.2576AGdel) was found that resulted in a frameshift mutation (818Tfs). Also, in the last exon, a point mutation (c.4647/3739C $>\mathrm{T}$ ) resulted in a nonsense mutation (Q1519stop, $\alpha$-synemin; Q1207stop, $\beta$-synemin). The location of the frame shift mutation and nonsense mutation is predicted to result in mutant ( $\alpha$ and $\beta$ ) synemin protein that will have altered/missing binding sites for sarcomeric and costameric binding partners. Thus, these mutations could have multiple effects on synemin functionality, particularly its role in crosslinking. The functional outcome of the point mutations is less obvious since these mutations are not within any known binding sites. However, in silico analysis has revealed that missense mutation W538R is predicted to disrupt local residue interaction (Paulin et al., 2020). Specifically, replacement of tryptophan (a neutral apolar hydrophobic residue) with arginine (a positive hydrophilic residue) is predicted to result in loss of interaction between residue 538 and residue leucine 541. This loss would disrupt a salt-bridge stabilizing the local $\alpha$-helix. The authors speculate that the proximity of this mutation to the PKA binding site would interfere with the ability of synemin to function as an AKAP.

\section{REFERENCES}

Aye, T. T., Soni, S., Van Veen, T. A., Van Der Heyden, M. A., Cappadona, S., Varro, A., et al. (2012). Reorganized PKA-AKAP associations in the failing human heart. J. Mol. Cell. Cardiol. 52, 511-518. doi: 10.1016/j.yjmcc.2011.06.003
A rare case of ulnar-mammary-like syndrome was found to be caused by a mutation in synemin (Zlotina et al., 2018). Ulnarmammary-like syndrome is one of a group of poorly understood "heart-hand" type syndromes that affect both the heart and limbs. Typically, they are caused by mutations in transcription factors such as $T B X 5, T B X 3$, or TFAP $2 B$, or an IF protein encoding nuclear lamins. In this study, the patient presented with cardiac dysfunctions including heart septal fibrosis and non-sustained left ventricular tachycardia. Additionally, she displayed pathology of the 5th digit, mental disability, and hypoplasia of the mammary glands. Due to this phenotype, the most likely causative mutation was predicted to be in $T B X 3$, however this gene was not found to be altered. After the use of whole-exome sequencing and focusing on genes expressed in all tissues affected by the syndrome, 14 genes were identified. A mutant synemin gene was among this group and identified as the logical candidate gene. The point mutation $(\mathrm{c} .173 \mathrm{C}>\mathrm{T})$ resulted in the missense mutation A58V in the rod domain (Figure 1). This position is conserved across mammals. Studies in transgenic mice described above support the possibility of mutant synemin causing this condition. Specifically, in these animals, a lack of synemin led to heart defects and bone abnormalities. Mutation at this location not only might prevent synemin from inclusion in the IF network, but also from interaction with the other, non-IF binding partners that bind to the rod domain (Figure1).

\section{CONCLUSION}

What is known about the role of synemin is evolving. It is an intermediate filament protein. It is a crosslinker. It is also a critical regulator of signaling pathways. Which functionality is dominant is isoform-, developmental-, and tissue-specific. What is clear is that it plays a critical role in the heart as emphasized by the clinical outcomes due to mutations in synemin and the results in mice lacking synemin. Work toward therapeutic applications using synemin will necessitate a better understanding of its different functions in an isoform-, developmental-, and tissuespecific manner.

\section{AUTHOR CONTRIBUTIONS}

MR wrote and edited the manuscript.

\section{ACKNOWLEDGMENTS}

I would like to thank J. Johnson for insightful review and J. McDonald for critical editing of the manuscript.

Becker, B., Bellin, R. M., Sernett, S. W., Huiatt, T. W., and Robson, R. M. (1995). Synemin contains the rod domain of intermediate filaments. Biochem. Biophys. Res. Commun. 213, 796-802. doi: 10.1006/bbrc.1995.2200

Bellin, R. M., Huiatt, T. W., Critchley, D. R., and Robson, R. M. (2001). Synemin may function to directly link muscle cell intermediate filaments to both 
myofibrillar Z-lines and costameres. J. Biol. Chem. 276, 32330-32337. doi: 10.1074/jbc.m104005200

Bellin, R. M., Sernett, S. W., Becker, B., Ip, W., Huiatt, T. W., and Robson, R. M. (1999). Molecular characteristics and interactions of the intermediate filament protein synemin. Interactions with alpha-actinin may anchor synemincontaining heterofilaments. J. Biol. Chem. 274, 29493-29499. doi: 10.1074/jbc. 274.41.29493

Bhosle, R. C., Michele, D. E., Campbell, K. P., Li, Z., and Robson, R. M. (2006). Interactions of intermediate filament protein synemin with dystrophin and utrophin. Biochem. Biophys. Res. Commun. 346, 768-777. doi: 10.1016/j.bbrc. 2006.05.192

Bilak, S. R., Sernett, S. W., Bilak, M. M., Bellin, R. M., Stromer, M. H., Huiatt, T. W., et al. (1998). Properties of the novel intermediate filament protein synemin and its identification in mammalian muscle. Arch. Biochem. Biophys. 355, 63-76. doi: 10.1006/abbi.1998.0702

Brancaccio, M., Hirsch, E., Notte, A., Selvetella, G., Lembo, G., and Tarone, G. (2006). Integrin signalling: the tug-of-war in heart hypertrophy. Cardiovasc. Res. 70, 422-433. doi: 10.1016/j.cardiores.2005.12.015

Brum, G., Osterrieder, W., and Trautwein, W. (1984). Beta-adrenergic increase in the calcium conductance of cardiac myocytes studied with the patch clamp. Pflugers Arch. 401, 111-118. doi: 10.1007/bf00583870

Calejo, A. I., and Tasken, K. (2015). Targeting protein-protein interactions in complexes organized by A kinase anchoring proteins. Front. Pharmacol. 6:192. doi: 10.3389/fphar.2015.00192

Callaghan, N. I. (2016). $\beta$-Adrenergic augmentation of cardiac contractility is dependent on PKA-mediated phosphorylation of myosin-binding protein C and troponin I. J. Physiol. 594, 4707-4708. doi: 10.1113/jp272333

Capetanaki, Y., Bloch, R. J., Kouloumenta, A., Mavroidis, M., and Psarras, S. (2007). Muscle intermediate filaments and their links to membranes and membranous organelles. Exp. Cell Res. 313, 2063-2076. doi: 10.1016/j.yexcr.2007.03.033

Carlsson, L., Li, Z. L., Paulin, D., Price, M. G., Breckler, J., Robson, R. M., et al. (2000). Differences in the distribution of synemin, paranemin, and plectin in skeletal muscles of wild-type and desmin knock-out mice. Histochem. Cell Biol. 114, 39-47. doi: 10.1007/s004180000158

Carnegie, G. K., Means, C. K., and Scott, J. D. (2009). A-kinase anchoring proteins: from protein complexes to physiology and disease. IUBMB Life 61, 394-406. doi: 10.1002/iub.168

Cenik, B. K., Liu, N., Chen, B., Bezprozvannaya, S., Olson, E. N., and Bassel-Duby, R. (2016). Myocardin-related transcription factors are required for skeletal muscle development. Development 143, 2853-2861. doi: 10.1242/dev.135855

Coulombe, P. A., and Wong, P. (2004). Cytoplasmic intermediate filaments revealed as dynamic and multipurpose scaffolds. Nat. Cell Biol. 6, 699-706. doi: 10.1038/ncb0804-699

Cutroneo, G., Lentini, S., Favaloro, A., Anastasi, G., and Mauro, D. D. (2012). Costameric proteins: from benchside to future translational cardiovascular research. Ann. Cardiol. Angéiol. 61, 55-60. doi: 10.1016/j.ancard.2011.12.003

de Souza Martins, S. C., Agbulut, O., Diguet, N., Larcher, J. C., Paulsen, B. S., Rehen, S. K., et al. (2011). Dynamic expression of synemin isoforms in mouse embryonic stem cells and neural derivatives. BMC Cell Biol. 12:51. doi: 10.1186/ 1471-2121-12-51

Dhalla, N. S., and Müller, A. L. (2010). Protein kinases as drug development targets for heart disease therapy. Pharmaceuticals 3, 2111-2145. doi: 10.3390/ ph3072111

Eriksson, J. E., Dechat, T., Grin, B., Helfand, B., Mendez, M., Pallari, H. M., et al. (2009). Introducing intermediate filaments: from discovery to disease. J. Clin. Invest. 119, 1763-1771. doi: 10.1172/JCI38339

Ervasti, J. M. (2003). Costameres: the Achilles' heel of herculean muscle. J. Biol. Chem. 278, 13591-13594. doi: 10.1074/jbc.r200021200

Feliciello, A., Gottesman, M. E., and Avvedimento, E. V. (2001). The biological functions of A-kinase anchor proteins. J. Mol. Biol. 308, 99-114. doi: 10.1006/ jmbi.2001.4585

Fink, M. A., Zakhary, D. R., Mackey, J. A., Desnoyer, R. W., Apperson-Hansen, C., Damron, D. S., et al. (2001). AKAP-mediated targeting of protein kinase a regulates contractility in cardiac myocytes. Circ. Res. 88, 291-297. doi: 10.1161/ 01.res.88.3.291

Fuchs, E., and Weber, K. (1994). Intermediate filaments: structure, dynamics, function, and disease. Annu. Rev. Biochem. 63, 345-382. doi: 10.1146/annurev. bi.63.070194.002021
Gao, Q. Q., and McNally, E. M. (2015). The dystrophin complex: structure, function, and implications for therapy. Compr. Physiol. 5, 1223-1239. doi: 10.1002/cphy.c140048

Garcia-Pelagio, K. P., Chen, L., Joca, H. C., Ward, C., Jonathan Lederer, W., and Bloch, R. J. (2018). Absence of synemin in mice causes structural and functional abnormalities in heart. J. Mol. Cell. Cardiol. 114, 354-363. doi: 10.1016/j.yjmcc. 2017.12.005

Garcia-Pelagio, K. P., Muriel, J., O’neill, A., Desmond, P. F., Lovering, R. M., Lund, L., et al. (2015). Myopathic changes in murine skeletal muscle lacking synemin. Am. J. Physiol. Cell Physiol. 308, C448-C462. doi: 10.1152/ajpcell.00331.2014

Geisler, N., and Weber, K. (1982). The amino acid sequence of chicken muscle desmin provides a common structural model for intermediate filament proteins. EMBO J. 1, 1649-1656. doi: 10.1002/j.1460-2075.1982.tb01368.x

Granger, B. L., and Lazarides, E. (1980). Synemin: a new high molecular weight protein associated with desmin and vimentin filaments in muscle. Cell 22, 727-738. doi: 10.1016/0092-8674(80)90549-8

Granger, B. L., and Lazarides, E. (1982). Structural associations of synemin and vimentin filaments in avian erythrocytes revealed by immunoelectron microscopy. Cell 30, 263-275. doi: 10.1016/0092-8674(82)90032-0

Granger, B. L., Repasky, E. A., and Lazarides, E. (1982). Synemin and vimentin are components of intermediate filaments in avian erythrocytes. J. Cell Biol. 92, 299-312. doi: 10.1083/jcb.92.2.299

Greenwald, E. C., and Saucerman, J. J. (2011). Bigger, better, faster: principles and models of AKAP anchoring protein signaling. J. Cardiovasc. Pharmacol. 58, 462-469. doi: 10.1097/FJC.0b013e31822001e3

Guerette, D., Khan, P. A., Savard, P. E., and Vincent, M. (2007). Molecular evolution of type VI intermediate filament proteins. BMC Evol. Biol. 7:164. doi: 10.1186/1471-2148-7-164

Henderson, C. A., Gomez, C. G., Novak, S. M., Mi-Mi, L., and Gregorio, C. C. (2017). Overview of the muscle cytoskeleton. Compr. Physiol. 7, 891-944. doi: 10.1002/cphy.c160033

Herrmann, H., and Aebi, U. (2000). Intermediate filaments and their associates: multi-talented structural elements specifying cytoarchitecture and cytodynamics. Curr. Opin. Cell Biol. 12, 79-90. doi: 10.1016/s09550674(99)00060-5

Herrmann, H., and Aebi, U. (2004). Intermediate filaments: molecular structure, assembly mechanism, and integration into functionally distinct intracellular scaffolds. Annu. Rev. Biochem. 73, 749-789. doi: 10.1146/annurev.biochem.73. 011303.073823

Herrmann, H., and Aebi, U. (2016). Intermediate filaments: structure and assembly. Cold Spring Harb. Perspect. Biol. 8:a018242. doi: 10.1101/cshperspect. a018242

Hidalgo, C., and Granzier, H. (2013). Tuning the molecular giant titin through phosphorylation: role in health and disease. Trends Cardiovasc. Med. 23, 165171. doi: 10.1016/j.tcm.2012.10.005

Hijikata, T., Nakamura, A., Isokawa, K., Imamura, M., Yuasa, K., Ishikawa, R., et al. (2008). Plectin 1 links intermediate filaments to costameric sarcolemma through beta-synemin, alph $\alpha$-dystrobrevin and actin. J. Cell Sci. 121(Pt 12), 2062-2074. doi: 10.1242/jcs.021634

Hirako, Y., Yamakawa, H., Tsujimura, Y., Nishizawa, Y., Okumura, M., Usukura, J., et al. (2003). Characterization of mammalian synemin, an intermediate filament protein present in all four classes of muscle cells and some neuroglial cells: colocalization and interaction with type III intermediate filament proteins and keratins. Cell Tissue Res. 313, 195-207. doi: 10.1007/s00441-003-0732-2

Hol, E. M., and Pekny, M. (2015). Glial fibrillary acidic protein (GFAP) and the astrocyte intermediate filament system in diseases of the central nervous system. Curr. Opin. Cell Biol. 32, 121-130. doi: 10.1016/j.ceb.2015.02.004

Izmiryan, A., Cheraud, Y., Khanamiryan, L., Leterrier, J. F., Federici, T., Peltekian, E., et al. (2006). Different expression of synemin isoforms in glia and neurons during nervous system development. Glia 54, 204-213. doi: 10.1002/glia.20378

Izmiryan, A., Franco, C. A., Paulin, D., Li, Z., and Xue, Z. (2009). Synemin isoforms during mouse development: multiplicity of partners in vascular and neuronal systems. Exp. Cell Res. 315, 769-783. doi: 10.1016/j.yexcr.2008.12.009

Izmiryan, A., Peltekian, E., Federici, T., Paulin, D., Li, Z. L., and Xue, Z. G. (2010). Synemin isoforms in astroglial and neuronal cells from human central nervous system. Neurochem. Res. 35, 881-887. doi: 10.1007/s11064-009-0111-9

Jing, R., Pizzolato, G., Robson, R. M., Gabbiani, G., and Skalli, O. (2005). Intermediate filament protein synemin is present in human reactive and 
malignant astrocytes and associates with ruffled membranes in astrocytoma cells. Glia 50, 107-120. doi: 10.1002/glia.20158

Jing, R., Wilhelmsson, U., Goodwill, W., Li, L., Pan, Y., Pekny, M., et al. (2007). Synemin is expressed in reactive astrocytes in neurotrauma and interacts differentially with vimentin and GFAP intermediate filament networks. J. Cell Sci. 120(Pt 7), 1267-1277. doi: 10.1242/jcs.03423

Jones, J. C., Kam, C. Y., Harmon, R. M., Woychek, A. V., Hopkinson, S. B., and Green, K. J. (2017). Intermediate filaments and the plasma membrane. Cold Spring Harb. Perspect. Biol. 9:a025866. doi: 10.1101/cshperspect.a025866

Karczewski, P., Kuschel, M., Baltas, L. G., Bartel, S., and Krause, E. G. (1997). Site-specific phosphorylation of a phospholamban peptide by cyclic nucleotideand $\mathrm{Ca} 2+/$ calmodulin-dependent protein kinases of cardiac sarcoplasmic reticulum. Basic Res. Cardiol. 92(Suppl. 1), 37-43. doi: 10.1007/bf00794066

Kawamura, N., Kugimiya, F., Oshima, Y., Ohba, S., Ikeda, T., Saito, T., et al. (2007). Akt1 in osteoblasts and osteoclasts controls bone remodeling. PLoS One 2:e1058. doi: 10.1371/journal.pone.0001058

Khanamiryan, L., Li, Z., Paulin, D., and Xue, Z. (2008). Self-assembly incompetence of synemin is related to the property of its head and rod domains. Biochemistry 47, 9531-9539. doi: 10.1021/bi800912w

Klapholz, B., and Brown, N. H. (2017). Talin - the master of integrin adhesions. J. Cell Sci. 130:jcs.190991. doi: 10.1242/jcs.190991

Knudsen, E. S., and Knudsen, K. E. (2008). Tailoring to RB: tumour suppressor status and therapeutic response. Nat. Rev. Cancer 8, 714-724. doi: 10.1038/ $\operatorname{nrc} 2401$

Kritzer, M. D., Li, J., Dodge-Kafka, K., and Kapiloff, M. S. (2011). AKAPs: the architectural underpinnings of local cAMP signaling. J. Mol. Cell. Cardiol. 52, 351-358. doi: 10.1016/j.yjmcc.2011.05.002

Langlois, B., Belozertseva, E., Parlakian, A., Bourhim, M., Gao-Li, J., Blanc, J., et al. (2017). Vimentin knockout results in increased expression of sub-endothelial basement membrane components and carotid stiffness in mice. Sci. Rep. 7:11628. doi: 10.1038/s41598-017-12024-z

Lee, J., and Kim, S. S. (2009). The function of p27 KIP1 during tumor development. Exp. Mol. Med. 41, 765-771. doi: 10.3858/emm.2009.41.11.102

Lester, L. B., and Scott, J. D. (1997). Anchoring and scaffold proteins for kinases and phosphatases. Recent Prog. Horm. Res. 52, 409-429; discussion 429-430.

Li, Y., Dowbenko, D., and Lasky, L. A. (2002). AKT/PKB phosphorylation of p21Cip/WAF1 enhances protein stability of p21Cip/WAF1 and promotes cell survival. J. Biol. Chem. 277, 11352-11361. doi: 10.1074/jbc.m109062200

Li, Z., Parlakian, A., Coletti, D., Alonso-Martin, S., Hourde, C., Joanne, P., et al. (2014). Synemin acts as a regulator of signalling molecules during skeletal muscle hypertrophy. J. Cell Sci. 127(Pt 21), 4589-4601. doi: 10.1242/jcs. 143164

Liang, J., and Slingerland, J. M. (2003). Multiple roles of the PI3K/PKB (Akt) pathway in cell cycle progression. Cell Cycle 2, 339-345.

Lowery, J., Kuczmarski, E. R., Herrmann, H., and Goldman, R. D. (2015). Intermediate filaments play a pivotal role in regulating cell architecture and function. J. Biol. Chem. 290, 17145-17153. doi: 10.1074/jbc.R115. 640359

Luna, G., Lewis, G. P., Banna, C. D., Skalli, O., and Fisher, S. K. (2010). Expression profiles of nestin and synemin in reactive astrocytes and Muller cells following retinal injury: a comparison with glial fibrillar acidic protein and vimentin. Mol. Vis. 16, 2511-2523.

Lund, L. M., Kerr, J. P., Lupinetti, J., Zhang, Y., Russell, M. A., Bloch, R. J., et al. (2012). Synemin isoforms differentially organize cell junctions and desmin filaments in neonatal cardiomyocytes. FASEB J. 26, 137-148. doi: 10.1096/fj.10179408

McGonnell, I. M., Grigoriadis, A. E., Lam, E. W., Price, J. S., and Sunters, A. (2012). A specific role for phosphoinositide 3-kinase and AKT in osteoblasts? Front. Endocrinol. (Lausanne) 3:88. doi: 10.3389/fendo.2012.00088

Mizuno, Y., Guyon, J. R., Okamoto, K., and Kunkel, L. M. (2007). Synemin expression in brain. Muscle Nerve 36, 497-504. doi: 10.1002/mus.20847

Mizuno, Y., Guyon, J. R., Okamoto, K., and Kunkel, L. M. (2009). Expression of synemin in the mouse spinal cord. Muscle Nerve 39, 634-641. doi: 10.1002/mus. 21221

Mizuno, Y., Thompson, T. G., Guyon, J. R., Lidov, H. G., Brosius, M., Imamura, M., et al. (2001). Desmuslin, an intermediate filament protein that interacts with alpha -dystrobrevin and desmin. Proc. Natl. Acad. Sci. U.S.A. 98, 6156-6161. doi: $10.1073 /$ pnas. 111153298
Moorer, M. C., Buo, A. M., Garcia-Pelagio, K. P., Stains, J. P., and Bloch, R. J. (2016). Deficiency of the intermediate filament synemin reduces bone mass in vivo. Am. J. Physiol. Cell Physiol. 311, C839-C845. doi: 10.1152/ajpcell.00218. 2016

Mukherjee, A., and Rotwein, P. (2009). Akt promotes BMP2-mediated osteoblast differentiation and bone development. J. Cell Sci. 122(Pt 5), 716-726. doi: 10. $1242 /$ jcs. 042770

Mukund, K., and Subramaniam, S. (2020). Skeletal muscle: a review of molecular structure and function, in health and disease. Wiley Interdiscip. Rev. Syst. Biol. Med. 12:e1462. doi: 10.1002/wsbm.1462

Mutlak, M., and Kehat, I. (2015). Extracellular signal-regulated kinases 1/2 as regulators of cardiac hypertrophy. Front. Pharmacol. 6:149. doi: 10.3389/fphar. 2015.00149

Noetzel, E., Rose, M., Sevinc, E., Hilgers, R. D., Hartmann, A., Naami, A., et al. (2010). Intermediate filament dynamics and breast cancer: aberrant promoter methylation of the Synemin gene is associated with early tumor relapse. Oncogene 29, 4814-4825. doi: 10.1038/onc.2010.229

Pan, Y., Jing, R., Pitre, A., Williams, B. J., and Skalli, O. (2008). Intermediate filament protein synemin contributes to the migratory properties of astrocytoma cells by influencing the dynamics of the actin cytoskeleton. FASEB J. 22, 3196-3206. doi: 10.1096/fj.08-106187

Parmacek, M. S. (2007). Myocardin-related transcription factors: critical coactivators regulating cardiovascular development and adaptation. Circ. Res. 100, 633-644. doi: 10.1161/01.res.0000259563.61091.e8

Paulin, D., Hovhannisyan, Y., Kasakyan, S., Agbulut, O., Li, Z., and Xue, Z. (2020). Synemin-related skeletal and cardiac myopathies: an overview of pathogenic variants. Am. J. Physiol. Cell Physiol. doi: 10.1152/ajpcell.00485.2019 [Epub ahead of print]

Paulin, D., Huet, A., Khanamyrian, L., and Xue, Z. (2004). Desminopathies in muscle disease. J. Pathol. 204, 418-427. doi: 10.1002/path.1639

Pekny, T., Faiz, M., Wilhelmsson, U., Curtis, M. A., Matej, R., Skalli, O., et al. (2014). Synemin is expressed in reactive astrocytes and rosenthal fibers in alexander disease. APMIS 122, 76-80. doi: 10.1111/apm.12088

Perkins, K. J., and Davies, K. E. (2002). The role of utrophin in the potential therapy of duchenne muscular dystrophy. Neuromuscul. Disord. 12(Suppl. 1), S78-S89.

Peter, A., and Stick, R. (2015). Evolutionary aspects in intermediate filament proteins. Curr. Opin. Cell Biol. 32, 48-55. doi: 10.1016/j.ceb.2014.12.009

Peter, A. K., Cheng, H., Ross, R. S., Knowlton, K. U., and Chen, J. (2011). The costamere bridges sarcomeres to the sarcolemma in striated muscle. Prog. Pediatr. Cardiol. 31, 83-88. doi: 10.1016/j.ppedcard.2011.02.003

Pitre, A., Davis, N., Paul, M., Orr, A. W., and Skalli, O. (2012). Synemin promotes AKT-dependent glioblastoma cell proliferation by antagonizing PP2A. Mol. Biol. Cell 23, 1243-1253. doi: 10.1091/mbc.E11-08-0685

Prudner, B. C., Roy, P. S., Damron, D. S., and Russell, M. A. (2014). alpha-synemin localizes to the M-band of the sarcomere through interaction with the M10 region of titin. FEBS Lett. 588, 4625-4630. doi: 10.1016/j.febslet.2014.11.001

Qi, L., Chen, K., Hur, D. J., Yagnik, G., Lakshmanan, Y., Kotch, L. E., et al. (2011). Genome-wide expression profiling of urinary bladder implicates desmosomal and cytoskeletal dysregulation in the bladder exstrophy-epispadias complex. Int. J. Mol. Med. 27, 755-765. doi: 10.3892/ijmm.2011.654

Quax-Jeuken, Y. E., Quax, W. J., and Bloemendal, H. (1983). Primary and secondary structure of hamster vimentin predicted from the nucleotide sequence. Proc. Natl. Acad. Sci. U.S.A. 80, 3548-3552. doi: 10.1073/pnas.80. 12.3548

Rose, B. A., Force, T., and Wang, Y. (2010). Mitogen-activated protein kinase signaling in the heart: angels versus demons in a heart-breaking tale. Physiol. Rev. 90, 1507-1546. doi: 10.1152/physrev.00054.2009

Rubashkin, M. G., Cassereau, L., Bainer, R., Dufort, C. C., Yui, Y., Ou, G., et al. (2014). Force engages vinculin and promotes tumor progression by enhancing PI3K activation of phosphatidylinositol $(3,4,5)$-triphosphate. Cancer Res. 74, 4597-4611. doi: 10.1158/0008-5472.CAN-13-3698

Russell, M. A., Lund, L. M., Haber, R., Mckeegan, K., Cianciola, N., and Bond, M. (2006). The intermediate filament protein, synemin, is an AKAP in the heart. Arch. Biochem. Biophys. 456, 204-215. doi: 10.1016/j.abb.2006. 06.010

Ruvolo, P. P. (2016). The broken “Off' switch in cancer signaling: PP2A as a regulator of tumorigenesis, drug resistance, and immune surveillance. $B B A$ Clin. 6, 87-99. doi: 10.1016/j.bbacli.2016.08.002 
Sanghvi-Shah, R., and Weber, G. F. (2017). Intermediate filaments at the junction of mechanotransduction, migration, and development. Front. Cell Dev. Biol. 5:81. doi: $10.3389 /$ fcell.2017.00081

Sarbassov, D. D., Guertin, D. A., Ali, S. M., and Sabatini, D. M. (2005). Phosphorylation and regulation of Akt/PKB by the rictor-mTOR complex. Science 307, 1098-1101. doi: 10.1126/science.1106148

Schmitt-Graeff, A., Jing, R., Nitschke, R., Desmouliere, A., and Skalli, O. (2006). Synemin expression is widespread in liver fibrosis and is induced in proliferating and malignant biliary epithelial cells. Hum. Pathol. 37, 1200-1210. doi: 10.1016/j.humpath.2006.04.017

Scott, J. D. (1991). Cyclic nucleotide-dependent protein kinases. Pharmacol. Ther. 50, 123-145. doi: 10.1016/0163-7258(91)90075-w

Shi, X., Wang, J., Lei, Y., Cong, C., Tan, D., and Zhou, X. (2019). Research progress on the PI3K/AKT signaling pathway in gynecological cancer (Review). Mol. Med. Rep. 19, 4529-4535.

Sjoblom, B., Salmazo, A., and Djinovic-Carugo, K. (2008). Alpha-actinin structure and regulation. Cell. Mol. Life Sci. 65, 2688-2701. doi: 10.1007/s00018-0088080-8

Steinert, P. M., Chou, Y. H., Prahlad, V., Parry, D. A., Marekov, L. N., Wu, K. C., et al. (1999). A high molecular weight intermediate filament-associated protein in BHK-21 cells is nestin, a type VI intermediate filament protein. Limited coassembly in vitro to form heteropolymers with type III vimentin and type IV alpha-internexin. J. Biol. Chem. 274, 9881-9890. doi: 10.1074/jbc.274.14.9881

Sultana, S., Sernett, S. W., Bellin, R. M., Robson, R. M., and Skalli, O. (2000). Intermediate filament protein synemin is transiently expressed in a subset of astrocytes during development. Glia 30, 143-153. doi: 10.1002/(sici)10981136(200004)30:2<143::aid-glia4>3.0.co;2-z

Sun, N., Critchley, D. R., Paulin, D., Li, Z., and Robson, R. M. (2008a). Human alpha-synemin interacts directly with vinculin and metavinculin. Biochem. J. 409, 657-667. doi: 10.1042/bj20071188

Sun, N., Critchley, D. R., Paulin, D., Li, Z., and Robson, R. M. (2008b). Identification of a repeated domain within mammalian alpha-synemin that interacts directly with talin. Exp. Cell Res. 314, 1839-1849. doi: 10.1016/j.yexcr. 2008.01.034

Sun, N., Huiatt, T. W., Paulin, D., Li, Z., and Robson, R. M. (2010). Synemin interacts with the LIM domain protein zyxin and is essential for cell adhesion and migration. Exp. Cell Res. 316, 491-505. doi: 10.1016/j.yexcr.2009.10.015

Sward, K., Krawczyk, K. K., Moren, B., Zhu, B., Matic, L., Holmberg, J., et al. (2019). Identification of the intermediate filament protein synemin/SYNM as a target of myocardin family coactivators. Am. J. Physiol. Cell Physiol. 317, C1128-C1142. doi: 10.1152/ajpcell.00047.2019

Tawk, M., Titeux, M., Fallet, C., Li, Z., Daumas-Duport, C., Cavalcante, L. A., et al. (2003). Synemin expression in developing normal and pathological human retina and lens. Exp. Neurol. 183, 499-507. doi: 10.1016/s0014-4886(03)002401

Titeux, M., Brocheriou, V., Xue, Z., Gao, J., Pellissier, J. F., Guicheney, P., et al. (2001). Human synemin gene generates splice variants encoding two distinct intermediate filament proteins. Eur. J. Biochem. 268, 6435-6449. doi: 10.1046/ j.0014-2956.2001.02594.x

Torres-Quesada, O., Mayrhofer, J. E., and Stefan, E. (2017). The many faces of compartmentalized PKA signalosomes. Cell. Signal. 37, 1-11. doi: 10.1016/j. cellsig.2017.05.012

Uyama, N., Zhao, L., Van Rossen, E., Hirako, Y., Reynaert, H., Adams, D. H., et al. (2006). Hepatic stellate cells express synemin, a protein bridging intermediate filaments to focal adhesions. Gut 55, 1276-1289. doi: 10.1136/gut.2005.07 8865

Vervoorts, J., and Luscher, B. (2008). Post-translational regulation of the tumor suppressor p27(KIP1). Cell. Mol. Life Sci. 65, 3255-3264. doi: 10.1007/s00018008-8296-7
Wang, D., Chang, P. S., Wang, Z., Sutherland, L., Richardson, J. A., Small, E., et al. (2001). Activation of cardiac gene expression by myocardin, a transcriptional cofactor for serum response factor. Cell 105, 851-862. doi: 10.1016/s00928674(01)00404-4

Ware, J. S., Li, J., Mazaika, E., Yasso, C. M., Desouza, T., Cappola, T. P., et al. (2016). Shared genetic predisposition in peripartum and dilated cardiomyopathies. N. Engl. J. Med. 374, 233-241. doi: 10.1056/NEJMoa1505517

Weisberg, A., and Winegrad, S. (1996). Alteration of myosin cross bridges by phosphorylation of myosin-binding protein C in cardiac muscle. Proc. Natl. Acad. Sci. U.S.A. 93, 8999-9003. doi: 10.1073/pnas.93.17.8999

Welch, E. J., Jones, B. W., and Scott, J. D. (2010). Networking with AKAPs: context-dependent regulation of anchored enzymes. Mol. Interv. 10, 86-97. doi: $10.1124 / \mathrm{mi} \cdot 10.2 .6$

Wiche, G., Osmanagic-Myers, S., and Castañón, M. J. (2015). Networking and anchoring through plectin: a key to IF functionality and mechanotransduction. Curr. Opin. Cell Biol. 32, 21-29. doi: 10.1016/j.ceb.2014.10.002

Xue, Z. G., Cheraud, Y., Brocheriou, V., Izmiryan, A., Titeux, M., Paulin, D., et al. (2004). The mouse synemin gene encodes three intermediate filament proteins generated by alternative exon usage and different open reading frames. Exp. Cell Res. 298, 431-444. doi: 10.1016/j.yexcr.2004. 04.023

Yoshida, A., Takahashi, M., Imagawa, T., Shigekawa, M., Takisawa, H., and Nakamura, T. (1992). Phosphorylation of ryanodine receptors in rat myocytes during beta-adrenergic stimulation. J. Biochem. 111, 186-190. doi: 10.1093/ oxfordjournals.jbchem.a123735

Yu, J. S. L., and Cui, W. (2016). Proliferation, survival and metabolism: the role of $\mathrm{PI} 3 \mathrm{~K} / \mathrm{AKT} / \mathrm{mTOR}$ signalling in pluripotency and cell fate determination. Development 143, 3050-3060. doi: 10.1242/dev. 137075

Zakhary, D. R., Fink, M. A., Ruehr, M. L., and Bond, M. (2000). Selectivity and regulation of A-kinase anchoring proteins in the heart. The role of autophosphorylation of the type II regulatory subunit of cAMP-dependent protein kinase. J. Biol. Chem. 275, 41389-41395. doi: 10.1074/jbc.m004212200

Zeller, R., Ivandic, B. T., Ehlermann, P., Mucke, O., Zugck, C., Remppis, A., et al. (2006). Large-scale mutation screening in patients with dilated or hypertrophic cardiomyopathy: a pilot study using DGGE. J. Mol. Med. (Berl.) 84, 682-691. doi: 10.1007/s00109-006-0056-2

Zhang, R., Zhao, J., Mandveno, A., and Potter, J. D. (1995). Cardiac troponin I phosphorylation increases the rate of cardiac muscle relaxation. Circ. Res. 76, 1028-1035. doi: 10.1161/01.res.76.6.1028

Zhang, S. B., Liu, Y. X., Fan, L. L., Huang, H., Li, J. J., Jin, J. Y., et al. (2018). A novel heterozygous variant p.(Trp538Arg) of SYNM is identified by whole-exome sequencing in a Chinese family with dilated cardiomyopathy. Ann. Hum. Genet. 83, 95-99. doi: 10.1111/ahg. 12287

Zlotina, A., Kiselev, A., Sergushichev, A., Parmon, E., and Kostareva, A. (2018). Rare case of ulnar-mammary-like syndrome with left ventricular tachycardia and lack of TBX3 mutation. Front. Genet. 9:209. doi: 10.3389/fgene.2018.00209

Conflict of Interest: The author declares that the research was conducted in the absence of any commercial or financial relationships that could be construed as a potential conflict of interest.

Copyright (c) 2020 Russell. This is an open-access article distributed under the terms of the Creative Commons Attribution License (CC BY). The use, distribution or reproduction in other forums is permitted, provided the original author(s) and the copyright owner(s) are credited and that the original publication in this journal is cited, in accordance with accepted academic practice. No use, distribution or reproduction is permitted which does not comply with these terms. 